\title{
FIToplankton: Wireless Controlled Remotely-operated Underwater Vehicle (ROV) for Shallow Water Exploration
}

\author{
Muhammad Ikhsan Sani ${ }^{1}$, Simon Siregar ${ }^{2}$, Aris Pujud Kurniawan ${ }^{3}$, M. Abid Irwan ${ }^{4}$ \\ ${ }^{1,2}$ Department of Computer Engineering, Faculty of Applied Science, Telkom University, Indonesia \\ ${ }^{3}$ Department of Computer System, Faculty of Electrical Engineering, Telkom University, Indonesia \\ ${ }^{4}$ Department of Telecommunication Engineering, Faculty of Applied Science, Telkom University, Indonesia
}

\begin{tabular}{l} 
Article Info \\
\hline Article history: \\
Received Nov 24, 2017 \\
Revised Feb 10, 2018 \\
Accepted Mar 3, 2018 \\
\hline Keyword: \\
Communication \\
Control \\
Remotely-operated \\
ROV \\
Underwater \\
Wireless
\end{tabular}

\begin{abstract}
Remotely Operated Vehicle (ROV) for underwater exploration is typically controlled using umbilical cable connected to ground control station. Unfortunately, while it's used for power distribution and data transmission, it also obstruct the movement of ROV especially for shallow water $(<50 \mathrm{~cm})$. This paper proposed an alternative method for controlling ROV using wireless remote control system. This work also aims to explore the possibility of using RF wireless technology between $420-450 \mathrm{MHz}$ as underwater communication system. Furthermore, the control system was used to manage actuators i.e. DC motor and bilge pump for maneuvring and picking small size cargo. To help the ROV to hold on a desired, Inertial Measurement Unit (IMU) is installed on board ROV within maximum deviation $0.2 \mathrm{~m} / \mathrm{s} 2$. The prototype of the system has been successfully implemented and evaluated to confirm the functionality and the feasibility of the proposed approach.
\end{abstract}

Copyright (c) 2018 Institute of Advanced Engineering and Science. All rights reserved.

\section{Corresponding Author:}

Muhammad Ikhsan Sani, Department of Computer Engineering, Faculty of Applied Science, Telkom University, Jalan Telekomunikasi Terusan Buah Batu, Bandung 40257, Jawa Barat, Indonesia. Email: m.ikhsan.sani@tass.telkomuniversity.ac.id

\section{INTRODUCTION}

For years, several remotely operated vehicles (ROVs) have been designed and implemented with different in shape and size. An ROV is typically tethered to a centralized platform ship to obtain power and transmitting data. ROV may sometimes be called Remotely Operated Underwater Vehicle to distinguish it from remote control vehicles operating on land or in the air [1]. According to the Christ \& Wernli (2013) [1], an ROV can be described as a submersible platform with self-propelled capability whose operation is either autonomous or manual control using data links such as a data cable. The ROV falls within a broad range of mobile robotic vehicles generally termed "remotely controlled mobile robots." The motion of the vehicle can be via autonomous logic direction or remote operator control depending upon the vehicle's capability and the operator's degree of input. Besides ROV, there is other type of underwater vehicle : Remotely Operated Crawler (ROC). While ROV is not designed to directly contact with the seabed, ROC is operated on the seabed to perform its task [2]

Azis. et al. (2012) [2] have described the advantages and disadvantages of ROV system in general view. Some of disadvantages of ROV are the issue with its dependency to umbilical cable and difficulty to access very shallow waters. Wiryadinata et. al. [3] have shown the method of ROV's control using Playstation joystick via UTP-based umbilical cable. The joystick serves as input signal's platform to a microcontroller. The signal that has been processed by a microcontroller will be sent to the motor driver to drive a DC motor. Their ROV's cable is designed using a a single strand of unshielded optical fiber for high 
speed data line. Although, its possible that the umbilical cable can hinder and disturb the ROV's movement especially in very shallow water.

Wireless remote control systems have been widely used as a controlling method on ground-based and aerial robot [4]. However, until recently only few researchers recently have carried out an experiment to explore the possibility for controlling ROV using wireless control system especially using RF technology. Some of their works are described as follow as shown in Figure 1.

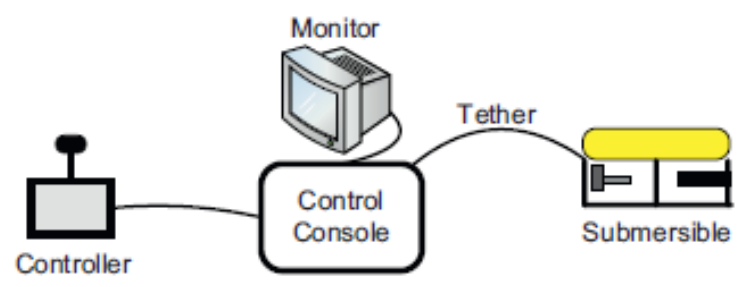

Figure 1. Basic ROV system [1]

Early work by Geol-Ju and Sung-Joon (2012) [5] has demonstrated a performance of prototype of a small-sized ROV operated by wireless communication. They also have tested the protoype using modem in a water tank and outdoor environments. Meanwhile, Lloret et. al (2012) [6] focused on the effect of depth and temperature for underwater sensor's data transmission using low frequency technology and acoustic. In their literature, Benelli and Pozzebon (2013) [7] states that ROV can be controlled using electromagnetic energy transmission capability through water. RF communications with underwater vehicles have a very limited usage due to the high attenuation of RF waves through water. However, this can be useful for shallow water and short range communication application.

Aras et. al. (2013) [8] state that beside the wireless control method it is also important to improve the control system using motion sensor. It helps maintaining ROV on its desired position. The integrated sensor combination has been developed and it consists of pressure sensor, Inertial Measurement Unit (IMU), digital compass and temperature sensor in a pressure hull that is purposely used to give a feedback to control the movement of the ROV. The target of heave-axis motion is to maintain its stationary and stabilize point or also called as "station keeping". Campagnaro et. Al. (2014) [9] focused their research on exploring the possibility of controlling a ROV using wireless control channel by optical, acoustic, and radio-frequency underwater communication technologies, as a function of the distance between the transmitter and the receiver.Meanwhile, previous work by Arumugaraja et. al (2015) [10] has demonstrated that $433 \mathrm{MHz}$ RF transceiver module can be utilized for ROV's controlling on shallow water. From these information, we can conclude that there is a possibilities for using wireless RF frequency for ROV controlling on shallow water.

This paper presents an alternative method for controlling ROV without using wireless radio communication. This work aims to develop ROV that can be used on shallow water exploration. The rest of this paper is organized as follows. Section 2 describes a literature review from related works conducted by several researcher. The development of FIToplankton by Robotic-SAS team from Telkom University is presented in section 3. Section 3 also details out the methodology of this project which includes system identification and data acquisition technique. Section 4 describes result and discussion from the experiments. Finally, section 5 shows the final remarks of conclusion.

\section{RESEARCH METHOD}

The FIToplankton project is divided into two major parts, hardware development and software development:

\subsection{Hardware Development}

Hardware phase development is described as follow: 1) Literature review of ROV mechanic, electronic and communication system, 2) Design and implementation communication device between ROV and remote control system, 3) Evaluation and troubleshooting the ROV hardware system on water tank. The first phase for developing the hardware is by having preliminary study and design the ROV structure, sensors and related communication device. Figure 2 and 3 shows the ROV block diagram. This phase is focus on how to choose the suitable sensors and also to know details about ROV construction and structure. The types 
of communication device also review on this phase. Meanwhile, the wireless remote control block diagram is shown in Figure 4 and 5. The following are specifications for the designed system: 1) ROV would be able to moving forward, backward, up, down, left, and right in the water, 2) Wireless communication system is used on remote control, 3) Battery level measurements data will be sent to remote control, 4) ROV is designed with relatively small size $(29.6 \times 26.66 \times 15.5 \mathrm{~cm})$. ROV system specification as shown in Table 1.

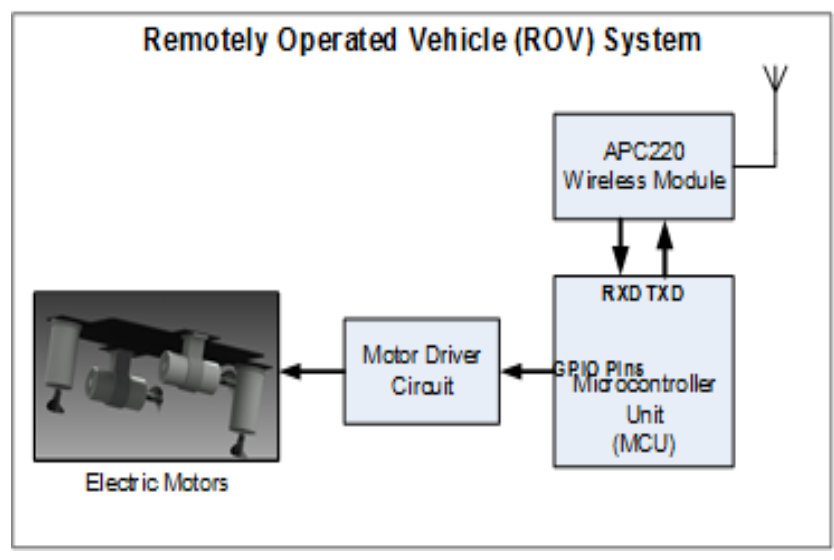

Figure 2. ROV block diagram
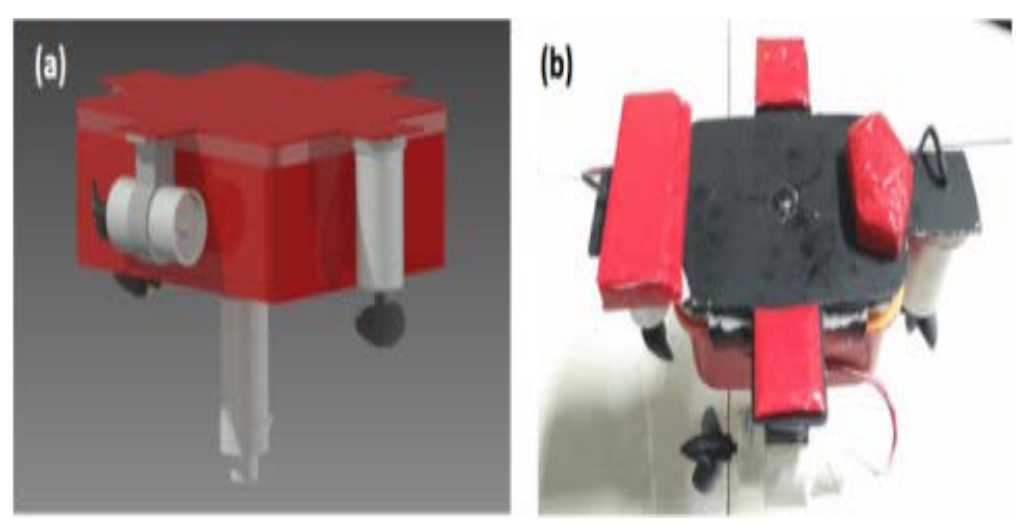

Figure 3. ROV implementation (a) concept design (b) ROV is operated underwater

Table 1. ROV System Specification

\begin{tabular}{cc}
\hline Part Name & Specification \\
\hline Microcontroller & ATmega2560 \\
\hline Communication System & $\begin{array}{c}\text { APC 220, 420 - 450 MHz } \\
\text { receiver module }\end{array}$ \\
\hline Power Supply & $\begin{array}{c}\text { 2-Cell Li-Po Battery 7.4 V } \\
500 \mathrm{mAH}\end{array}$ \\
\hline \multirow{2}{*}{ Sensor } & $\begin{array}{c}10-\text { DOF Inertial } \\
\end{array}$ \\
\hline Propulsion System & 4 pieces DC Motor \\
\hline Motor Driver & L293D-based Motor Driver \\
\hline Manipulator & Bilge Pump \\
\hline Dimension & 29.6 x 26.66 x 15.5 cm \\
\hline
\end{tabular}

The remote control system is equipped by game console joystick for user interface. Arrow button and analog joystick are served as direction control to move the ROV forward, backward, turn left and right. The X-button is used to lower and raise the ROV. To activate bilge pump for taking the cargo, the square must be pressed. Wireless control system as shown in Table 2. 
Table 2. Wireless Control System

\begin{tabular}{cc}
\hline Part Name & Specification \\
\hline Controller platform & PS2 Joystick with analog button \\
\hline Communication System & $\begin{array}{c}\text { APC 220, 420 - 450 MHz } \\
\text { transmitter module }\end{array}$ \\
\hline Power Supply & 2-Cell Li-Po Battery 7.4 V 500 \\
mAH
\end{tabular}

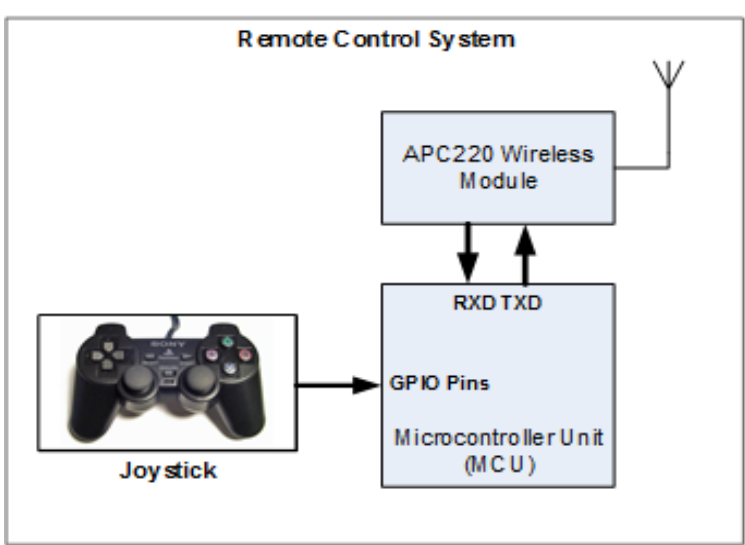

Figure 4. ROV remote control system

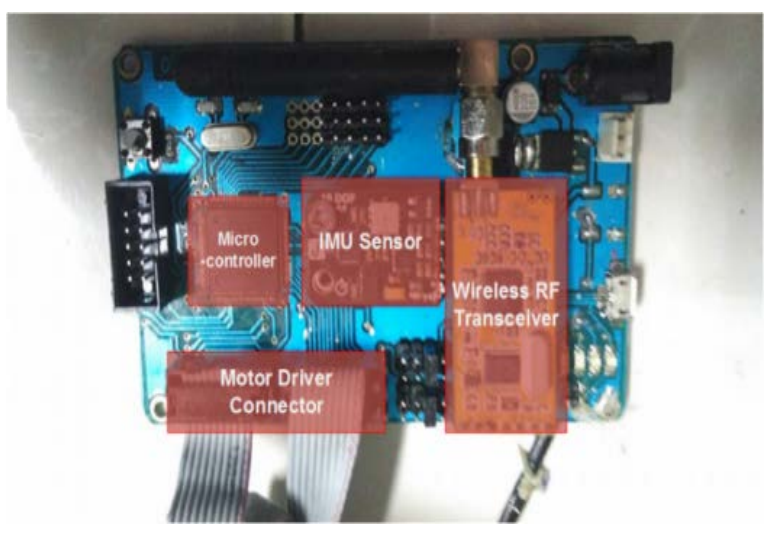

Figure 5. Wireless remote control implementation

\subsection{Software Development}

The software part can be divided into three phases: 1. Design and implementation of ROV's software: data input, data processing and data communication, 2. Design and implementation of remote control system for simulation, data input, data storage, processing and other ROV key instruction control, 3. Hardware and software communication setting and testing. Figure 6 shows the flowchart that used for the software of ROV control system.

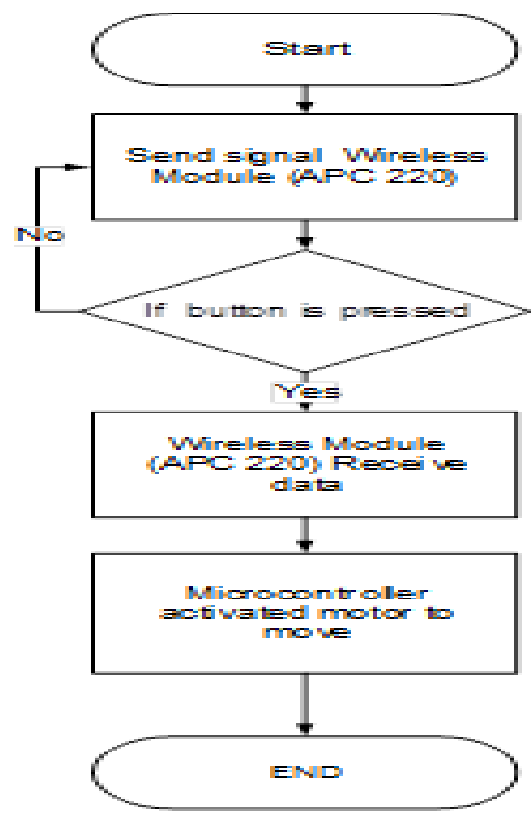

Figure 6. ROV's software flowchart 


\section{RESULTS AND ANALYSIS}

\subsection{Wireless Remote Control Experiment Result}

After implementation, system is tested on L-shaped water tank and its depth is $40 \mathrm{~cm}$ as shown in Figure 7. This test is conducted to evaluate its ability i.e. signal penetration on water. This result is depend on value of water conductivity is known, it can be used to calculate the values of the signal's penetration depth. The penetration depth $\delta$ (in centimeter) can be calculated using the following formula [5]:

$$
\delta=\frac{1}{\sqrt{\pi f \mu \sigma}}
$$

Where $f$ is frequency of the electromagnetic wave, $\mu$ is absolute magnetic permeability of the conductor, $\sigma$ is water conductivity and $\mu$ is water's magnetic permeability that assumed same as the vacuum magnetic permeability $\left(\mu_{0}=4 \pi \times 10^{-7} \mathrm{H} / \mathrm{m}\right)$.

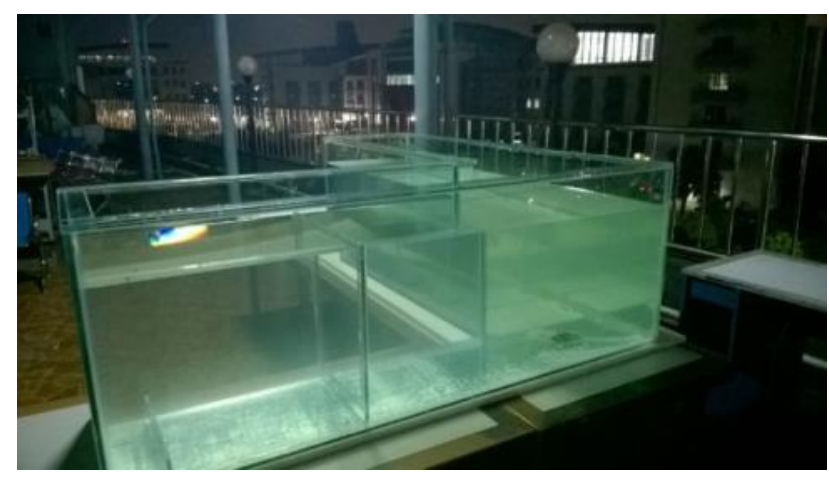

Figure 7. Water tank for experiment

The water conductivity is assumed constant. Fresh water conductivity typically varies between from $30 \mu \mathrm{S} / \mathrm{cm}-2000 \mu \mathrm{S} / \mathrm{cm}$ [5]. The penetration depth value will be calculated both for the best $(30 \mu \mathrm{S} / \mathrm{cm})$ and the worst $(2000 \mu \mathrm{S} / \mathrm{cm})$ case. In this case, at the frequency of 420,433 , and $450 \mathrm{MHz}$ from APC220 transceiver module. For example, the value of penetration depth at $433 \mathrm{MHz}$ can be calculated using Equation 1 with a conductivity value respectively of $30 \mu \mathrm{S} / \mathrm{cm}(3 \mathrm{mS} / \mathrm{m})$ and $2000 \mu \mathrm{S} / \mathrm{cm}(0.2 \mathrm{~S} / \mathrm{m})$. The results are shown on equation (2) and (3).

$$
\begin{aligned}
& \delta_{433 \mathrm{MHz}}=\frac{1}{\sqrt{\pi \cdot 433 \cdot 10^{6} \cdot 4 \pi \cdot 10^{-7} \cdot 3 \cdot 10^{-3}}} \approx 44.16 \mathrm{~cm} \\
& \delta_{433 \mathrm{MHz}}=\frac{1}{\sqrt{\pi \cdot 433 \cdot 10^{6} \cdot 4 \pi \cdot 10^{-7} \cdot 0.2}} \approx 5.4 \mathrm{~cm}
\end{aligned}
$$

With same equation, it can be also calculated the signal penetration using various frequency for comparison as shown in Table 3. From Table 3, it can be concluded that the signal's penetration depth depends on the frequency. The higher is the frequency, the lower is the signal's penetration depth. This result indicates that wireless communication using UHF 420-450 MHz can be used for controlling ROV on shallow water $(<50$ $\mathrm{cm})$.

Table 3. Wireless Signal under Water Penetration using Various Frequency

\begin{tabular}{ccccc}
\hline \multirow{2}{*}{ Water Type } & UHF & UHF & UHF & UHF \\
\cline { 2 - 5 } & $420 \mathrm{MHz}$ & $433 \mathrm{MHz}$ & $450 \mathrm{MHz}$ & $2,4 \mathrm{GHz}$ \\
\hline $\begin{array}{c}\text { Fresh Water } \\
\text { (Conductivity } \\
30 \mu \text { S/cm) }\end{array}$ & 44.84 & 44.16 & 43.32 & 18.6 \\
\hline $\begin{array}{c}\text { Fresh Water } \\
\text { (Conductivity } \\
2000 \mu \mathrm{S} / \mathrm{cm})\end{array}$ & 5.49 & 5.4 & 5.4 & 2.3 \\
\hline
\end{tabular}




\subsection{Control System Experimental Result}

This test is intended to evaluate between key presses and the movement of the ROV especially DC motor for maneuvring and manipulator for collecting cargo as shown in Figure 8. Control system experiment result (a) forward and reverse (b) down (c) left \& right (d) up as shown in Figure 9. The result of the test can be seen in Table 4. Table 4 shows that keystrokes control the direction that has been made in accordance with the program so that the movement of the ROV navigation in accordance with the command given.

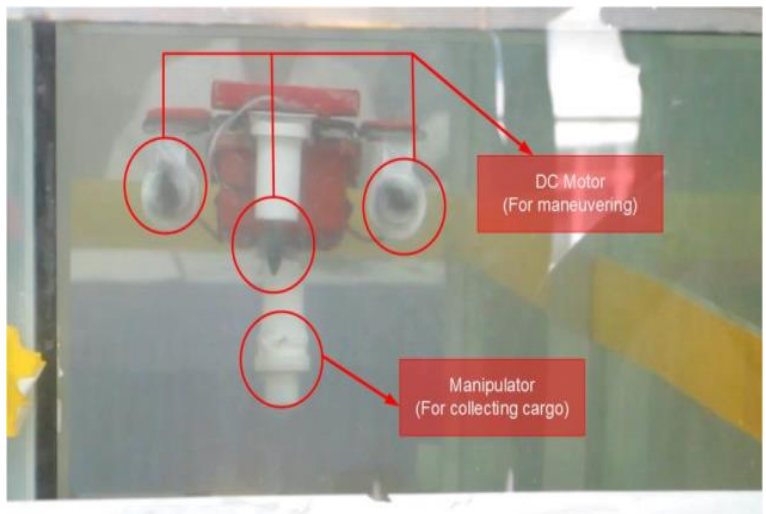

Figure 8. Control system experiment object

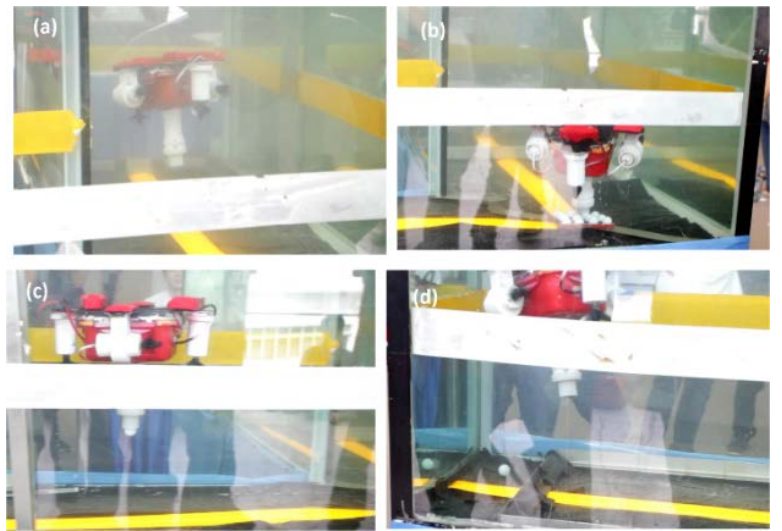

Figure 9. Control system experiment result (a) forward and reverse (b) down (c) left \& right (d) up

Table 4. Remote Control Test Result

\begin{tabular}{cccccccccc}
\hline \multirow{2}{*}{ No } & \multicolumn{1}{c}{ Input Button } & \multicolumn{7}{c}{ Output } & \multirow{2}{*}{ Direction } \\
\cline { 2 - 9 } & $\uparrow$ & $\downarrow$ & $\rightarrow$ & $\leftarrow$ & M1 & M2 & M3 & M4 & \\
\hline 1. & 1 & 0 & 0 & 0 & H & H & L & H & Forward \\
\hline 2. & 0 & 1 & 0 & 0 & L & L & H & H & Reverse \\
\hline 3. & 0 & 0 & 1 & 0 & H & L & L & L & Turn Right \\
\hline 4. & 0 & 0 & 0 & 1 & L & H & L & L & Turn Left \\
\hline
\end{tabular}

\subsection{IMU Sensor Experiment}

IMU sensor must be calibrated to compensate earth gravity effect. Calibration test is done by placing the sensor module at a particular position as shown in Figure 10. Based on the plot of the graph in Figure 10 shows that the accelerometer test result within $2-4 \mathrm{~m} / \mathrm{s}^{2}$.

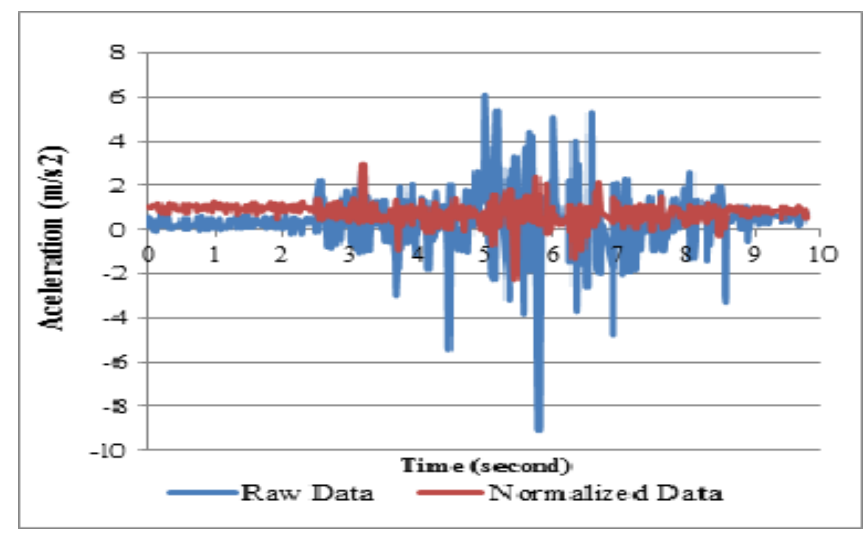

Figure 10. IMU sensor experiment result

The average value for all approached it with the value should be. There is a deviation that varies with a fairly small range. While the maximum deviation occurring is $0.2 \mathrm{~m} / \mathrm{s}^{2}$. The deviation value of the 
accelerometer is on the $\mathrm{Y}$ axis on the node 1. The test results on each sensor shows that there is a deviation value at each sensor node, but the resulting error can still be tolerated for this application.

\section{CONCLUSION}

This paper successfully presented an alternative method for developing small sized ROV control without umbilical cable using wireless remote control system. Firstly, it is possible to use RF for under water applications especially with the use of Ultra High Frequency (UHF) devices operating at 420-450 $\mathrm{MHz}$ on shallow water ( $<50 \mathrm{~cm}$ depth). Secondly, the system is programmed to take the cargo using modified bilge pump. Thirdly, the IMU sensor helps the ROV to hold a position within maximum deviation $0.2 \mathrm{~m} / \mathrm{s}^{2}$. Future works on this field should be directed at automated controlling system and camera installation for better monitoring system.

\section{ACKNOWLEDGEMENTS}

This research was supported by Penelitian Dana Internal (PDI) PPM Telkom University.

\section{REFERENCES}

[1] R. D. Christ and R. L. Wernli, The ROV Manual - A User Guide for Remotely Operated Vehicles The ROV Manual A User Guide for Remotely, 2nd ed. Elsevier, 2014.

[2] M. S. Mohd Aras, M. N. Kamarudin, M. H. Bin Che Rusli, and M. I. Mohd Zainal, "Small scale unmanned underwater remotely operated crawler (ROC),” Indones. J. Electr. Eng. Comput. Sci., vol. 3, no. 3, pp. 481-488, 2016.

[3] F. A. Azis, M. S. M. Aras, M. Z. A. Rashid, M. N. Othman, and S. S. Abdullah, "Problem identification for Underwater Remotely Operated Vehicle (ROV): A case study,” J. Procedia Eng., vol. 41, pp. 554-560, 2012.

[4] R. Wiryadinata, A. S. Nurliany, I. Muttakin, and T. Firmansyah, "Design of a Low Cost Remotely Operated Vehicle with 3 DoF Navigation,” Bull. Electr. Eng. Informatics, vol. 6, no. 1, pp. 13-23, 2017.

[5] M. Sudarma, I. B. A. Swamardika, and I. W. D. Pranata, "Design and Implementations of Control System Quadruped Robot Driver Application Based on Windows Platform,” Int. J. Electr. Comput. Eng., vol. 5, no. 2, pp. 251-258, 2015.

[6] G.-J. Kim and S.-J. Park, “A Wireless Remotely Operated Vehicle Using Acoustic Communication,” Mar. Technol. Soc. J., vol. 46, no. 3, pp. 44-49, May 2012.

[7] J. Lloret, S. Sendra, M. Ardid, and J. J. P. C. Rodrigues, "Underwater wireless sensor communications in the 2.4 GHz ISM frequency band,” Sensors, vol. 12, pp. 4237-4264, 2012.

[8] G. Benelli and A. Pozzebon, "RFID Under Water: Technical Issues and Applications," in Radio Frequency Identification from System to Applications, M. B. I. Reaz, Ed. InTechOpen, 2013, pp. 379-396.

[9] M. S. M. Aras, S. S. Abdullah, M. Z. A. Rashid, A. A. Rahman, and M. A. A. Aziz, "Development and modeling of unmanned underwater remotely operated vehicle using system identification for depth control,” J. Theor. Appl. Inf. Technol., vol. 56, no. 1, pp. 136-145, 2013.

[10] F. Campagnaro, F. Favaro, P. Casari, and M. Zorzi, "On the feasibility of fully wireless remote control for underwater vehicles,” in 48th Asilomar Conference on Signals, Systems and Computers, 2015, pp. 33-38.

[11] M. Arumugaraja, R. Kaviya, A. Janani, and P. Thivyanagammai, “Design of Underwater Robot,” Int. J. Innov. Res. Sci. Eng. Technol., vol. 4, no. 4, pp. 64-71, 2015. 


\section{BIOGRAPHIES OF AUTHORS}

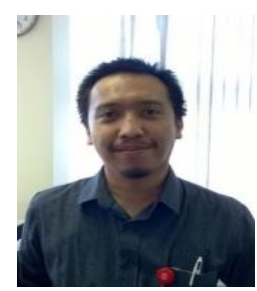

Muhammad Ikhsan Sani is graduated from Institut Teknologi Bandung (ITB) at 2008. His special fields of interest included embedded system, robotics, and electronic circuit desing. His employment experience included the Microelectronics Center and LAPI ITB. He joined Telkom University in 2015 as a lecturer at D3 Computer Engineering program, Faculty of Applied Science.

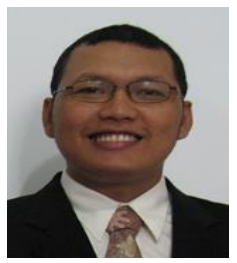

Simon Siregar is a lecturer since 2007 at Department of Computer Engineering, Faculty of Applied Science, Telkom University. He graduated from Institut Teknologi Bandung (ITB) at 2009 and his special fields of interest are Internet of Things, Roboctic and Control System.

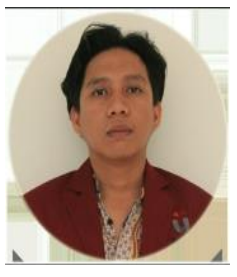

Muhammad Abid Irwan is Student from Institut Universitas Telkom. His special fields of interest included Telecommunication engineering, robotics, Design Mechanical 3D and electronic circuit design. His employment experience included group Research Robotic at Robotic Schools of Applied Sicence in Telkom University.

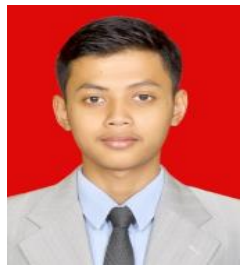

Aris Pujud Kurniawan is student of Telkom University. His specialties are robotics, programming, electronics and embedded system. His work experience included a member of Robotic Research Group, Faculty of Applied Science, Telkom University. Recently, he has joined an IT company as a programmer. 